\title{
Factors associated with emotional exhaustion in undergraduate and postgraduate nursing students
}

\author{
M Engelbrecht, ${ }^{1} \mathrm{PhD} ; \mathrm{M}$ Wilke, ${ }^{2} \mathrm{PhD}$ \\ ${ }^{1}$ Centre for Health Systems Research \& Development, Faculty of the Humanities, University of the Free State, Bloemfontein, South Africa \\ ${ }^{2}$ School of Nursing, Faculty of Health Sciences, University of the Free State, Bloemfontein, South Africa
}

Corresponding author: M Engelbrecht (engelmc@ufs.ac.za)

\begin{abstract}
Background. Nursing students face dual stress from a combination of academic and clinical demands, which may affect their emotional wellbeing. Poor emotional wellbeing may prevent them from gaining the necessary knowledge and skills to care for patients.

Objectives. To describe and compare levels of emotional exhaustion, personal accomplishment, compassion satisfaction, compassion fatigue and perceived stress of undergraduate and postgraduate nursing students, and to determine the influence of compassion fatigue, perceived stress and disengaged coping on emotional exhaustion.

Methods. This study was a cross-sectional descriptive survey at a purposively selected South African university. There were 685 students, of whom $471(68.8 \%)$ completed the questionnaire, which comprised a biographical section, as well as standardised and validated scales.

Results. The respondents obtained a moderate score for perceived stress and were at average risk for emotional exhaustion and compassion fatigue. There were statistically significant differences between undergraduates and postgraduates on all scales, with undergraduates faring the worst. Stress from assignments and workload, lack of professional knowledge and skills, teachers and nursing staff and compassion fatigue made a statistically significant contribution to the prediction of emotional exhaustion in undergraduates. Compassion fatigue and stress from assignments and workload made a statistically significant contribution to the prediction of emotional exhaustion in postgraduates.

Conclusion. Nursing students had moderate stress scores and were at average risk for emotional exhaustion and compassion fatigue, with undergraduate students faring the worst. Schools of nursing should prioritise the emotional wellbeing of their students, particularly that of undergraduates.
\end{abstract}

Afr J Health Professions Educ 2021;13(2):140-144. https://doi.org/10.7196/AJHPE.2021.v13i2.1300

The backbone of a caring nurse is compassion, when nurses have feelings of empathy for the suffering of others and understand patients' personal feelings or experiences without being judgemental. ${ }^{[1]}$ As a result, nursing is particularly stressful, ${ }^{[2-4]}$ as nurses not only cope with their personal stress but also with secondary forms of stress due to the nature of their interaction with patients and their families. Nursing students may be more vulnerable to the harmful effects of secondary stress, as they are developing the skills necessary to fulfil their professional roles effectively. ${ }^{[5]}$ They are also faced with academic stressors, ${ }^{[5-11]}$ such as practical training in environments characterised by high patient loads, insufficient resources and long working hours; ${ }^{[12]}$ lack of professional knowledge and skills; ${ }^{[5]}$ and unclear roles and responsibilities. ${ }^{[8,10]}$

While nursing education fosters empathy and compassion in the student nurse to prepare them for their professional role of caring for others, ${ }^{[13]}$ ongoing empathetic and compassionate behaviour and stress pave the way for burnout and compassion fatigue. ${ }^{[12,13]}$ Burnout is a combination of negative behavioural, attitudinal and physical changes in response to work-related stress. ${ }^{[14]}$ Burnout or compassion fatigue among nursing students may result in students failing to acquire the knowledge and skills needed to care for their patients. This situation has a domino effect on the quality of care, which could expose patients to healthcare-related risks. ${ }^{[15]}$

With this in mind, this article describes the emotional wellbeing of undergraduate and postgraduate nursing students at a university in South
Africa (SA). Wellbeing was defined by levels of emotional exhaustion, personal accomplishment, compassion satisfaction, compassion fatigue and perceived stress. More specifically, the objectives of the study were to:

- describe levels of emotional exhaustion, personal accomplishment, compassion fatigue, compassion satisfaction and perceived stress experienced by nursing students

- compare levels of emotional exhaustion, personal accomplishment, compassion satisfaction, compassion fatigue and perceived stress of undergraduate and postgraduate nursing students

- determine the influence of compassion fatigue, perceived stress and disengaged coping on emotional exhaustion of undergraduate and postgraduate nursing students.

\section{Methods \\ Design and sample}

A cross-sectional descriptive survey was undertaken at a purposively selected SA university. There was a total of 685 registered undergraduate $(n=333)$ and postgraduate $(n=352)$ nursing students at the university. Four hundred and seventy-one questionnaires (258 undergraduate and 213 postgraduate) were returned $(68.8 \%$ response rate), of which 27 were discarded owing to extensive missing data, leaving a total of 444 completed questionnaires (252 undergraduate and 192 postgraduate). 


\section{Data collection}

At the start of each class, students received an envelope with an information leaflet, consent form and questionnaire. The class co-ordinator allowed time for students who wished to participate in the study to complete the questionnaire. Completed questionnaires and consent forms were returned in a sealed envelope.

\section{Measures}

The first section of the questionnaire collected demographic and background information (e.g. sex, age, marital status, dependants, home language, place of residence, payment of university fees and year of study). The second section comprised the following standardised and validated scales:

- The Maslach burnout inventory, which assesses three dimensions of burnout, i.e. emotional exhaustion, depersonalisation and personal accomplishment. ${ }^{[14]}$ Reliability and validity were found acceptable for SA nurses. ${ }^{[4]}$ Scoring for this scale is as follows: emotional exhaustion - low score $\leq 18$, average score $19-26$, high score $\geq 27$; depersonalisation - low score $\leq 5$, average score 6 - 9 , high score $\geq 10$; and personal accomplishment - low score $\geq 40$, average score 39 - 40, high score $\leq 33 .^{[14]}$

- The professional quality of life (ProQoL) scale measures compassion fatigue, burnout and compassion satisfaction. ${ }^{[16]}$ SA studies with nurses report good levels of internal consistency for two sub-scales, i.e. compassion satisfaction and compassion fatigue. ${ }^{[17]}$ For all scales, a low-risk cut-off score was set at a total sum of $\leq 22$, between 23 and 41 for average risk, and $\geq 42$ for high risk. ${ }^{[16]}$

- The perceived stress scale measures stress from taking care of patients; teachers and nursing staff; assignments and workload; peers and daily life; lack of professional knowledge and skills; and clinical environment. ${ }^{[18]}$ Cronbach's $\alpha$ of 0.87 was reported for the total scale among Filipino nursing students. ${ }^{[5]}$ The following cut-off points have been suggested: $2.67-4.00$ for high levels of perceived stress; $1.34-2.66$ for moderate levels of perceived stress; and 0 - 1.33 for low levels of perceived stress. ${ }^{[5,18]}$

- The coping strategies inventory short form measures engaged and disengaged coping styles. ${ }^{[19,20]}$

\section{Data analysis}

Data were double captured, cleaned and analysed in SPSS version 25 (IBM Corp., USA). Descriptive statistics were generated yielding frequency counts and percentages for categorical variables, and means and standard deviations (SDs) for continuous variables. Composite scores were calculated for all sub-scales. Cronbach's a was used to test the internal consistency of the scales and sub-scales. The independent sample $t$-test was used to determine if there was a difference between undergraduate and postgraduate students on the mean scores for emotional exhaustion, personal accomplishment, compassion satisfaction, compassion fatigue, perceived stress and coping strategies. Standard multiple regression was performed to predict emotional exhaustion for undergraduate and postgraduate nursing students from compassion fatigue, perceived stress and disengaged coping.

\section{Ethical approval}

Before data collection early in October 2018, ethical clearance was obtained from the Ethics Committee, Faculty of Economic and Management Sciences, University of the Free State, Bloemfontein (ref. no. UFS-HSD2017/1097).
The various scales were purchased/accessed in line with their copyright agreements.

\section{Results}

\section{Reliability analysis}

An a value of 0.7 is considered a sufficient measure of reliability. ${ }^{[21]}$ Therefore, scales with alpha $<0.7$ were eliminated from further analyses (Table 1).

\section{Biographical characteristics}

The majority of respondents were female $(88.5 \%)$ and the average ages of undergraduates and postgraduates were 21.8 years and 37.1 years, respectively. Two-thirds of postgraduates (67\%) were married or in a longterm relationship compared with $30.9 \%$ of undergraduates. While most postgraduate students lived at home with family $(61.8 \%)$, undergraduates mostly stayed in student houses off campus (37.7\%) or at home (24.6\%). Two-thirds of postgraduates paid for their own studies (67.7\%), while undergraduates reported having bursaries (44.6\%) or their parents paid for their studies (37.8\%) (Table 2).

\section{Perceived stress}

Overall, nursing students obtained a moderate score on the perceived stress scale (mean (SD) $1.48(0.61)$ ). There was a statistically significant difference between undergraduates $(1.72(0.53))$ who fell in the 'moderate' category, and postgraduates $(1.15(0.55))$ who fell in the 'low' stress category (95\% confidence interval (CI) $0.47-0.68 ; t(442)=11.094 ; p=0.000$ ). A closer look revealed significant differences between undergraduate and postgraduate students on all sub-scales. More specifically, undergraduates had moderate scores on all sub-scales while postgraduates had low scores on stress from taking care of patients $(0.87(0.56))$, lack of professional knowledge and skills $(0.66(0.76))$, the environment $(1.16(0.78))$ and teachers and nursing staff (1.06 (0.73)) (Table 3).

\begin{tabular}{lll} 
Table 1 . Reliability of the scales & & \\
\hline Scales & Items, $\boldsymbol{n}$ & Cronbach's $\boldsymbol{\alpha}$ \\
\hline Maslach burnout inventory & 22 & \\
Emotional exhaustion & 9 & 0.86 \\
Depersonalisation & 5 & 0.55 \\
Personal accomplishment & 8 & 0.76 \\
Professional quality of life & 30 & \\
Compassion satisfaction & 10 & 0.85 \\
Burnout & 10 & 0.63 \\
Compassion fatigue & 10 & 0.75 \\
Perceived stress scale & 29 & 0.93 \\
Stress from taking care of patients & 8 & 0.80 \\
Stress from assignments and workload & 5 & 0.85 \\
Stress from lack of professional knowledge & 3 & 0.92 \\
and skills & & \\
Stress from the environment & 3 & 0.67 \\
Stress from peers and daily life & 4 & 0.71 \\
Stress from teachers and nursing staff & 6 & 0.81 \\
Coping strategies (short form) & 16 & \\
Engaged coping & 8 & 0.76 \\
Disengaged coping & 8 & 0.70 \\
& &
\end{tabular}




\section{Burnout}

The student nurses scored an average of 24.83 (11.62) (range 0 - 54) on the emotional exhaustion sub-scale, indicating an average risk for burnout. There was a statistically significant difference in the mean emotional exhaustion scores between undergraduates $(26.01(10.87))$ and postgraduates $(23.28$ (12.38)) $(95 \%$ CI $0.56-4.91 ; t(442)=2.471 ; p=0.016)$. The mean scores for undergraduates suggest that they were close to a high risk for emotional exhaustion, where scoring guidelines indicate that $\geq 27$ is a high score. ${ }^{[14]}$ At the other end of the spectrum, student nurses had a high score on personal accomplishment $(26.35$; 6.42 ; range 0 - 48). There was a statistically significant difference between undergraduates and postgraduates on feelings of personal accomplishment (95\% CI $-2.80--0.40 ; t(442)=-2.623 ; p=0.009)$. Postgraduates had a higher mean score on personal accomplishment $(27.26$ (6.53)) than undergraduates (25.66 (6.26)) (Table 3).

\section{Compassion fatigue and satisfaction}

An average of 24.03 (6.14) was scored on the compassion fatigue sub- scale, an indication of average levels. Undergraduates scored higher on compassion fatigue $(25.19(5.8))$ than postgraduates $(22.51(6.26))$. This statistically significant difference $(95 \%$ CI $1.56-3.82 ; t(442)=4.674 ; p=0.000)$ places undergraduates at an average risk and postgraduates at a low risk for compassion fatigue. Average levels of compassion satisfaction were recorded (40.16 (6.34)), with a statistically significant difference between undergraduates $(39.59 ; 6.67)$ and postgraduates $(40.91$ (5.81)) $(95 \%$ CI -2.51 $--1.35 ; t(442)=-2.189)$ (Table 3$)$.

\section{Engaged coping}

The students had an overall mean score of 27.55 (5.12) for engaged coping. There was a statistically significant difference between postgraduates (28.66 (5.14)), who scored higher than undergraduates (26.71 (4.95)) (95\% CI $-2.90--1.00) ; t(424)=-4.043 ; p=0.000)$. The mean score for disengaged coping was 23.44 (5.24), and differed significantly for undergraduates (24.83 (5.24)) and postgraduates $(21.62(5.21))(95 \%$ CI $2.27-4.16) ; t(242)=6.716 ; p=0.000)$ (Table 3).

\begin{tabular}{|c|c|c|c|}
\hline & Total $(N=444), n(\%)$ & Undergraduate $(N=252), n(\%)$ & Postgraduate $(N=192), n(\%)$ \\
\hline \multicolumn{4}{|l|}{ Sex } \\
\hline Male & $51(11.5)$ & $18(7.1)$ & $33(17.2)$ \\
\hline Female & $393(88.5)$ & $234(92.9)$ & $159(82.8)$ \\
\hline Married/in a long-term relationship* & $203(46.5)$ & $77(30.9)$ & $126(67.0)$ \\
\hline \multicolumn{4}{|l|}{ Place of residence ${ }^{\dagger}$} \\
\hline At home with family & $180(40.6)$ & $62(24.6)$ & $118(61.8)$ \\
\hline Student house off campus & $127(28.7)$ & $95(37.7)$ & $32(16.8)$ \\
\hline Rent accommodation off campus & $75(16.9)$ & $36(14.3)$ & $39(20.4)$ \\
\hline Residence on campus & $61(13.8)$ & $59(23.4)$ & $2(1.0)$ \\
\hline \multicolumn{4}{|l|}{ Payment of university fees ${ }^{\ddagger}$} \\
\hline Bursary & $154(35.2)$ & $111(44.6)$ & $43(22.8)$ \\
\hline Self-funded & $135(30.8)$ & $7(2.8)$ & $128(67.7)$ \\
\hline Parents pay & $94(21.5)$ & $94(37.8)$ & - \\
\hline Student loan & $55(12.6)$ & $37(14.9)$ & $18(9.5)$ \\
\hline
\end{tabular}

\begin{tabular}{|c|c|c|c|c|}
\hline Scales & Total, mean (SD) & Undergraduate, mean (SD) & Postgraduate, mean (SD) & $p$-value \\
\hline \multicolumn{5}{|l|}{ Maslach burnout inventory } \\
\hline Emotional exhaustion & $24.83(11.62)$ & $26.01(10.87)$ & $23.28(12.38)$ & 0.016 \\
\hline Personal accomplishment & $26.35(6.42)$ & $25.66(6.26)$ & $27.26(6.53)$ & 0.009 \\
\hline \multicolumn{5}{|l|}{ Professional quality of life } \\
\hline Compassion satisfaction & $40.16(6.34)$ & $39.59(6.67)$ & $40.91(5.81)$ & 0.260 \\
\hline Compassion fatigue & $24.03(6.14)$ & $25.19(5.80)$ & $22.51(6.26)$ & 0.000 \\
\hline Perceived stress scale & $1.48(0.61)$ & $1.72(0.53)$ & $1.15(0.55)$ & 0.000 \\
\hline Stress from taking care of patients & $1.14(0.62)$ & $1.35(0.58)$ & $0.87(0.56)$ & 0.000 \\
\hline Stress from assignments and workload & $2.23(0.96)$ & $2.54(0.87)$ & $1.82(0.90)$ & 0.000 \\
\hline Stress from lack of professional knowledge and skills & $1.06(0.86)$ & $1.37(0.80)$ & $0.66(0.76)$ & 0.000 \\
\hline Stress from the environment & $1.36(0.76)$ & $1.52(0.71)$ & $1.16(0.78)$ & 0.000 \\
\hline Stress from peers and daily life & $1.71(0.86)$ & $1.98(0.79)$ & $1.36(0.83)$ & 0.000 \\
\hline Stress from teachers and nursing staff & $1.39(0.78)$ & $1.65(0.72)$ & $1.06(0.73)$ & 0.000 \\
\hline \multicolumn{5}{|l|}{ Coping strategies (short form) } \\
\hline Engaged coping & $27.55(5.12)$ & $26.71(4.95)$ & $28.66(5.14)$ & 0.000 \\
\hline Disengaged coping & $23.44(5.24)$ & $24.83(4.83)$ & $21.62(5.21)$ & 0.000 \\
\hline
\end{tabular}




\section{Prediction of emotional exhaustion}

Multiple regressions were run to predict emotional exhaustion in undergraduate and postgraduate nursing students from stress from taking care of patients; assignments and workload; lack of professional knowledge and skills; the environment; peers and daily life; teachers and nursing staff; as well as compassion fatigue and disengaged coping (Tables 4 and 5). The assumptions of linearity, independence of errors, homoscedasticity, unusual points and normality residuals were met.

For undergraduate nursing students (Table 4), these variables were statistically significant in predicting emotional exhaustion $(F(9.243)=1.517$; $p=0.000$; adjusted $\left.R^{2}=0.358\right)$. Compassion fatigue $(t=5.587 ; p=0.000)$, stress from assignments and workload $(t=6.020 ; p=0.000)$, stress from lack of professional knowledge and skills $(t=-2.837 ; p=0.005)$ and stress from teachers and nursing staff $(t=2.531 ; p=0.012)$ made a statistically significant unique contribution to the prediction of emotional exhaustion. Stress from assignments and workload $(\beta=0.412)$ was the highest predictor of emotional exhaustion, followed by compassion fatigue $(\beta=0.314)$ and stress from teachers and nursing staff $(\beta=0.159)$.

For postgraduate nursing students, these variables were statistically significant in predicting emotional exhaustion $(F(8.183)=9.954 ; p=0.000$; adjusted $\left.R^{2}=0.273\right)$ (Table 5). Compassion fatigue $(t=4.470 ; p=0.000)$ and stress from assignments and workload $(t=3.289 ; p=0.001)$ made a statistically significant unique contribution to the prediction of emotional exhaustion. Compassion fatigue $(\beta=0.310)$ was the highest predictor of emotional exhaustion, followed by stress from assignments and workload $(\beta=0.249)$.

\section{Discussion}

University students in general, ${ }^{[8,22]}$ and nursing students in particular, ${ }^{[5-11]}$ experience numerous stressors during their academic life, which affect their emotional wellbeing. This is the first cross-sectional study investigating and comparing the emotional wellbeing of undergraduate and postgraduate nursing students in SA.
Overall, we found that nursing students had moderate stress scores and were at average risk for emotional exhaustion and compassion fatigue. More specifically, undergraduate students had higher levels of perceived stress, compassion fatigue and emotional exhaustion than postgraduate students.

In his research, Labrague ${ }^{[5]}$ found that senior nursing students have less stress than junior students. A possible explanation is that, as students obtain more experience, they perceive less stress. It is, however, important to keep in mind that academic and occupational stress is inevitable, even necessary at times, but it should not need to lead to dysfunction. This can be avoided if preventive stress management and enhanced wellbeing strategies are in place. In this regard, the scores on perceived stress, compassion fatigue and emotional exhaustion suggest that nursing students may not have appropriate stress management strategies. More specifically, undergraduates, with higher scores on emotional exhaustion, compassion fatigue and perceived stress, also scored higher on disengaged coping, a negative strategy that sees the individual not sharing their feelings with others, avoiding thoughts about situations and not initiating behaviours that could change the situation. However, postgraduate students, who had lower levels of emotional exhaustion, compassion fatigue and perceived stress, scored higher on engaged coping, which is a positive strategy that sees the individual engage in active and ongoing negotiation with the stressful event. ${ }^{[19]}$ While research suggests that coping mechanisms have a great influence on the occurrence of burnout, ${ }^{[23]}$ we did not find a significant association between type of coping strategy and emotional exhaustion in undergraduate or postgraduate students. Further research is necessary to inform strategies to prevent burnout in nursing students.

Significant predictors of emotional exhaustion among undergraduates were increased levels of compassion fatigue and stress from assignments and workload, as well as teachers and nursing staff. The finding that a decrease in stress from lack of professional knowledge and skills led to an increase in emotional exhaustion requires further research for clarification. Emotional exhaustion in postgraduates was significantly predicted by compassion

Table 4. Standard multiple regression analysis related to the prediction of emotional exhaustion in undergraduate nursing students

\begin{tabular}{llllll}
\hline Independent variables & B & Standard error & $\boldsymbol{\beta}$ & $\boldsymbol{t}$ & $\boldsymbol{p}$-value \\
\hline Compassion fatigue & 0.588 & 0.105 & 0.314 & 5.587 & 0.000 \\
Stress from taking care of patients & -0.616 & 1.261 & -0.033 & -0.488 & 0.626 \\
Stress from assignments/workload & 5.130 & 0.852 & 0.412 & 6.020 & 0.000 \\
Stress from lack of professional knowledge/skills & -2.398 & 0.845 & -0.177 & -2.837 & 0.005 \\
Stress from the environment & 0.104 & 0.918 & 0.007 & 0.114 & 0.910 \\
Stress from peers and daily life & -1.040 & 0.982 & -0.075 & -1.059 & 0.291 \\
Stress from teachers and nursing staff & 2.576 & 1.018 & 0.171 & 2.531 & 0.012 \\
Disengaged coping & -0.055 & 0.127 & -0.024 & -0.433 & 0.666
\end{tabular}

Table 5. Standard multiple regression analysis related to the prediction of emotional exhaustion in postgraduate nursing students

\begin{tabular}{llllll}
\hline Independent variables & B & Standard error & $\boldsymbol{\beta}$ & $\boldsymbol{t}$ & $\boldsymbol{p}$-value \\
\hline Compassion fatigue & 0.656 & 0.147 & 0.331 & 4.470 & 0.000 \\
Stress from taking care of patients & -2.500 & 1.853 & -0.114 & -1.349 & 0.179 \\
Stress from assignments/workload & 3.514 & 1.069 & 0.257 & 3.289 & 0.001 \\
Stress from lack of professional knowledge/skills & -1.337 & 1.288 & -0.082 & -1.038 & 0.301 \\
Stress from the environment & 0.478 & 1.257 & 0.030 & 0.380 & 0.704 \\
Stress from peers and daily life & 1.689 & 1.246 & 0.113 & 1.355 & 0.177 \\
Stress from teachers and nursing staff & 0.930 & 1.433 & 0.055 & 0.649 & 0.517 \\
Disengaged coping & 0.119 & 0.163 & 0.050 & 0.773 & 0.465
\end{tabular}


fatigue and stress from assignments and workload. According to Rudman and Gustavsson, ${ }^{[24]}$ increased levels of emotional exhaustion experienced during nurse education could have a sustained effect on an individual's health when entering professional working life. Following this line of reasoning, if studies are academically and practically (i.e. clinical training) demanding, it is also more likely that considerable resources will be needed to assist students to cope with the situation and recover from energy loss. Therefore, it is recommended that nursing educators take cognisance of the need to introduce effective and preventive measures to manage burnout - already at the outset of nursing education. In this regard, Demir et al. ${ }^{[25]}$ found that a peer mentoring intervention, where fourth-year nursing students mentored first-year nursing students, improved the ability of those in their first year to cope with stress. In line with this, and based on our findings, nursing schools should consider using postgraduate students, who seem to be doing better emotionally and who cope better with stress and emotional exhaustion. Clinical peer mentorship programmes are already in place at nursing schools and have been found to benefit mentors and mentees, ${ }^{[26,27]}$ and could be extended to include aspects of emotional wellbeing. This reciprocal relationship would then also benefit postgraduate students, who despite being at lower risk for emotional exhaustion still experienced this to a degree.

\section{Study limitations}

The study was conducted at one university among a convenience sample of undergraduate and postgraduate nursing students. We did, however, reach $68.8 \%$ of the total group of nursing students at the university. Nonetheless, the results cannot be generalised to other university settings. Our questionnaires were self-administered and, as with most self-reported measures, some level of response bias is likely. It could be helpful to supplement survey data with other data sources. Finally, we collected our data towards the end of the year, which could also have influenced the findings, as exams were approaching.

\section{Conclusion}

Overall, we found that nursing students had moderate stress scores and were at average risk for emotional exhaustion and compassion fatigue. There were significant differences between undergraduate and postgraduate students in terms of perceived stress, emotional exhaustion and compassion fatigue. It is evident that nursing schools should include a component focusing on the emotional wellbeing of their students, particularly undergraduate students. In this regard, peer mentorship of undergraduates by postgraduates should be considered. Further research is required to investigate the link between coping strategies and burnout, as this will be key to informing the type of assistance that should be available for nursing students.
Declaration. None.

Acknowledgements. None.

Author contributions. ME and MW designed the study and research instruments. ME analysed the data and prepared the manuscript. MW gave inputs on the manuscript. Both authors approved the final version for submission.

Funding. University of the Free State (interdisciplinary grant).

Conflicts of interest. None.

1. Williams J, Stickley T. Empathy and nurse education. Nurse Educ Today 2010;30(8):752-755. https://doi. org $/ 10.1016 /$ j.nedt.2010.01.018

. Dlamini BC, Visser M. Challenges in nursing: The psychological needs of rural area nurses in Mpumalanga. Remed Open Access 2017;2:1068

3. Khamisa N, Oldenburg B, Peltzer K, Ilic D. Work related stress, burnout, job satisfaction and general health of nurses. Int J Environ Res Public Health 2015;12(1):652-666. https://doi.org/10.3390/ijerph120100652

4. Van der Colff JJ, Rothmann S. Occupational stress of professional nurses in South Africa. J Psychol Afr 2014;24(4):375-384. https://doi.org/10.1080/14330237.2014.980626

5. Labrague LJ. Stress, stressors, and stress responses of student nurses in a government nursing school. Health Sci 2013;7(4):424-435.

6. Aslan H, Akturk U. Nursing education stress levels of nursing students and the associated factors. Ann Med Res 2018;5(4):660-666. https://doi.org/10.5455/annalsmedres.2018.06.108

. Langtree EM, Razak A, Haffejee F. Factors causing stress among first-year students attending a nursing college in KwaZulu-Natal, South Africa. Afr J Health Professions Educ 2018;10(2):90-95. https://doi. org/10.7196\%2FAJHPE.2018.v10i2.993

8. Tharania A, Husainb Y, Warwick I. Learning environment and emotional well-being: A qualitative study of undergraduate nursing students. Nurse Educ Today 2017;59:82-87. https://doi.org/10.1016/..nedt.2017.09.008 9. Turner T, McCarthy VL. Stress and anxiety among nursing students: A review of intervention strategies in literature between 2009 and 2015. Nurse Educ Pract 2017;22:21-29. https://doi.org/10.1016/j.nepr.2016.11.002 0. Sun L, Gao Y, Yang J, Zang XY, Wang YG. The impact of professional identity on role stress in nursing students A cross-sectional study. Int J Nurs Stud 2016;63:1-8. https://doi.org/10.1016/jijnurstu.2016.08.010

1. Khater WA, Akhu-Zaheya LM, Shaban IA. Sources of stress and coping behaviours in clinical practice among baccalaureate nursing students. Int J Hum Soc Sci 2014;4(6):194-202.

12. Mason HD, Nel JA. Compassion fatigue, burnout and compassion satisfaction: Prevalence among nursing students. J Psychol Afr 2012;22(3):451-455. https://doi.org/10.1080/14330237.2012.10820554

13. Mathias CT, Wentzel DL. Descriptive study of burnout, compassion fatigue and compassion satisfaction in undergraduate nursing students at a tertiary education institution in KwaZulu-Natal. Curationis 2017;40(1):el-e6. https://doi.org/10.4102/curationis.v40i1.1784

14. Maslach C, Leiter MP, Jackson SE. Maslach Burnout Inventory Manual. 3rd ed. Calif, USA: Mind Garden, 1996

15. Da Silva RM, Goulart CT, Lopes LFD, et al. Hardy personality and burnout syndrome among nursing students in three Brazilian universities - an analytic study BMC Nurs 2014:13(1):9. https://doi.org/10.1186/1472-6955-13-9 6. Stamm BH. The ProQOL Manual. 2005. http://www.compassionfatigue.org/pages/ProQOLManualOct05 pd (accessed 25 November 2019).

17. Wentzel DL, Brysiewicz P. A survey of compassion satisfaction, burnout and compassion fatigue in nurses practicing in three oncology departments in Durban, South Africa. Int J Afr Nurs Sci 2018:8:82-86. https.//dol. org/10.1016/.ijans.2018.03.004

18. Sheu S, Lin HS, Hwang SL. Perceived stress and physio-psycho-social status of nursing students during their initial period of clinical practice: The effect of coping behaviors. Int I Nurs Stud 2002;39(2):165-175. https://doi. org/10.1016/s0020-7489(01)00016-5

19. Tobin DL, Holroyd KA, Reynolds RV, Wigul JK. The hierarchical factor structure of the coping strategies inventory. Cognit Ther Res 1989;13:343-361.

20. Addison CC, Campbell-Jenkins BW, Sarpong DF, et al. Psychometric evaluation of a coping strategies inventory short-form (CSI-SF) in the Jackson Heart Study Cohort. Int J Environ Res Public Health 2007:4(4):289-295. https://doi.org/10.3390/ijerph200704040004

21. Taber KS. The use of Cronbach's alpha when developing and reporting research instruments in science education. Res Sci Educ 2018;48:1273. https://doi.org/10.1007/s11165-016-9602-2

22. Leppink EW, Odlaug BL, Lust K, Christenson G, Grant JE. The young and the stressed: Stress, impulse control, and health in college students. J Nerv Ment Dis 2016:204(12):931-938, https://doi.org/10:1097/ NMD.0000000000000586

23. Cumbe VFJ, Pala AN, Palha AJP, et al. Burnout syndrome and coping strategies in Portuguese oncology health care providers. Arch Clin Psychiatry 2017;44(5):122-126. https://doi.org/10.1590/0101-60830000000135

24. Rudman A, Gustavsson JP. Burnout during nursing education predicts lower occupational preparedness and future clinical performance: A longitudinal study. Int J Nurs Stud 2012;49(8):988-1001. https://doi.org/10.1016/j. ijnurstu. 2012.03 .010

25. Demir S, Demir SG, Bulut H, Hisar F. Effect of mentoring program on ways of coping with stress and locus of control for nursing students. Asian Nurs J 2014;8(4):254-260. https://doi.org/10.1016/j.anr.2014.10.004

26. Mlaba ZP Emmamally W. Describing the perceptions of student nurses regarding barriers and benefits of a peermentorship programme in a clinical setting in KwaZulu-Natal. Health SA Gesondheid 2019;24:a1118 httpe mentorship programme in a clinical setting in KwaZulu-Natal. Health SA Gesondheid 2019;24:a1118. https:/
doi.org/10.4102/hsag.v24i0.1118

7. Joubert $\mathrm{A}$, de Villiers $J$. The leani

programme. Curationis 2015;38(1):1145. https://doi.org/10.4102/curationis.v38i1.1145 